\title{
THEORETICAL STUDIES OF CHEMISORPTION AND SURFACE REACTIUNS \\ ON NICKEL AND SILICON
}

\author{
Final Report
}

for Period June 15, 1987 - September 14, 1990

\section{J. L. Whitten}

State University of New York at Stony Brook

Stony Brook, N.Y. 11794
DOE/ER/45100--14

DE91 004171

\author{
and \\ North Carolina State University
}

Raleigh, N.C. 27695

October 16, 1990

\author{
Prepared for \\ U.S. Departmeni of Energy \\ Grant DE-FG02-84ER45100.A008 \\ DISCLAIMER
}

\begin{abstract}
This report was prepared as an account of work sponsored by an agency of the. United States Government. Neither the United States Government nor any agency thereof, nor any of their employees, makes any warranty, express or implied, or assumes any legal liability or responsibility for the accuracy, completeness, or usefulness of any information, apparatus, product, or process disclosed, or represents that its use would not infringe privately owned rights. Reference herein to any specific commercial product, process, or service by trade name, trademark, manufacturer, or otherwise does not necessarily constitute or imply its endorsement, recommendarion, or favoring by the United States Government or any agency thereof. The views and opinions of authors expressed herein do not necessarily state or reflect those of the United States Government or any agency thereof.
\end{abstract}




\title{
Theoretical Studies of Chemisorption and Surface Reactiens
}

\author{
on Nickel and Silicon \\ Grant DE-FG02-84ER45100.A008 \\ Jerry L. Whitten \\ State University of New York at Stony Brook \\ and \\ North Carolina State University
}

\begin{abstract}
The research is part of a theoretical program on the structure of molecules adsorbed on solid surfaces and dissociative chemisorption with emphasis on transition metal substrates and electronic materials. An embedding theory for treating chemisorption on meta's is further developed and applied to the reaction of hydrocarbon fragments and hydrogen coadsorbed on nickel, the dissociation of water on nickel, and the systems $\mathrm{H} / \mathrm{Ni}, \mathrm{NH}_{3} / \mathrm{Ni}$, and $\mathrm{C}_{6} \mathrm{H}_{6} / \mathrm{Ni}$. The main emphasis of the work is on the energetics of adsorption as a function of surface site, the potential energy for adsorbate motion between surface sites and the energetics of surface reactions. Equilibrium geometries, vibrational frequencies and ionization potentials are also calculated. Preliminary work on the description of $\mathrm{Si}(100)$ surfaces has been completed in preparation of $\mathrm{H} / \mathrm{Si}$ and $\mathrm{N} / \mathrm{Si}$ adsorption studies. Studies of $\pi$ bonding on $\mathrm{Si}(111)$ were also completed and work was begun on the Auger ionization of $\mathrm{F} / \mathrm{Si}$. The original form of the embedding theory has been extended to make use of an effective potential representation of the bulk electrons interacting with the embedded surface region. Effective core potentials for Fe have been developed.
\end{abstract}




\section{Final Report}

The research is part of a theoretical program on the structure of molecules adsorbed on solid surfaces and dissociative chemisorption with emphasis on transition metal substrates and electronic materials. An embedding theory for treating chemisorption on metals is further developed and applied to the reaction of hydrocarbon fragments and hydrogen coadsorbed on nickel, the dissociation of water on nickel, and the systems $\mathrm{H} / \mathrm{Ni}, \mathrm{NH}_{3} / \mathrm{Ni}$, and $\mathrm{C}_{6} \mathrm{H}_{6} / \mathrm{Ni}$. The main emphasis of the work is on the energetics of adsorption as a function of surface site, the potential energy for adsorbate motion between surface sites and the energetics of surface reactions. Equilibrium geometries, vibrational frequencies and ionization potentials are also calculated. Studies of $\pi$ bonding on $\mathrm{Si}(111)$ were also completed and work was begun on the Auger ionization of $\mathrm{F} / \mathrm{Si}$.

The original form of the embedding theory has been extencied to make use of an effective potential representation of the bulk electrons interacting with the embedded surface region. Surface sites are described by an improved basis (radial, polarization and correlation functions), and in the case of transition metals by variable $\mathrm{d}$ occupancy. Electronic wavefunctions are constructed by configuration interaction and the coupling of the local subspace and adsorbate to the bulk lattice electrons, $\{\varphi\}$, defined by a localization transformation, is represented by a pseudopotential $(1,9,16)$.

$\Psi=\Sigma_{\mathrm{k}} \lambda_{\mathrm{k}} A_{1}\left(x_{1}^{\mathrm{k}} x_{2}^{\mathrm{k}} \ldots x_{\mathrm{n}}^{\mathrm{k}} \varphi_{\mathrm{m}}^{\prime} \ldots \varphi^{\prime}{ }_{\mathrm{N}}\right)$

linzal region pseudopotential

The nickel surface calculations are carried out by modelling the lattice as a 26 atom, three layer cluster which is extracted from a larger cluster by the orbital localization transformation. Hydrogen atoms are found to bind strongly to the $\mathrm{Ni}(111)$ surface at three-fold and bridge sites (13). Calculated $\mathrm{H}$ binding energies are in the range 2.50-2.66 $\mathrm{eV}$, for optimized $\mathrm{Ni}-\mathrm{H}$ bond lengths ranging from 1.81 to $1.87 \AA$. Vibrational frequencies are in the range $1043-1183 \mathrm{~cm}^{-1}$ These quantities are in excellent agreement 
with experiment. Work on the recombination reaction of hydrogen on nickel was also started during this period. Studies of $\mathrm{H}-\mathrm{H}$ interactions show a repulsive interaction for hydrogens adsorbed in adjacent three-fold sites that share two nickel atoms compared to separated three-fold sites sharing only one nickel atom. Similar behavior was found in earlier studies of hydrogen adsorbed on $\mathrm{Ti}(0001)$.

The following reactions have been studied in detail on $\operatorname{Ni}(111)(9,10)$ :

$$
\mathrm{CH}+\mathrm{H}=\mathrm{CH}_{2} \quad \mathrm{CH}_{2}+\mathrm{H}=\mathrm{CH}_{3} \quad \mathrm{CH}_{3}+\mathrm{H}=\mathrm{CH}_{4}
$$

Energetics and structural information are obtained for the $\mathrm{CH}, \mathrm{CH}_{2}, \mathrm{CH}_{3}$ and $\mathrm{H}$ species at the most stable sites on $\mathrm{Ni}(111)$ and for intermediate steps along the reaction pathway. Both $\mathrm{CH}$ and $\mathrm{CH}_{2}$ species are found to bind strongly to the surface at three-fold and bridge sites. A three-fold site is the ri:ost stable for $\mathrm{CH}_{3}$ with indistinguishable adsorption energies for filled or hollow sites. Adsorption energies are between 2.9 and $3.1 \mathrm{eV}$ for $\mathrm{CH}$ adsorption, 2.5 and $2.9 \mathrm{eV}$ for $\mathrm{CH}_{2}$ adsorption and $1.7 \mathrm{eV}$ for $\mathrm{CH}_{3}$. Atop $\mathrm{Ni}$ adsorption sites are more than $1 \mathrm{eV}$ higher in energy. The Ni-C bond lengths range from 2.00 to $2.04 \AA$ for $\mathrm{CH}$ and $\mathrm{CH}_{2}$ on the surface. Vibrational frequencies for HC-surface and $\mathrm{H}_{2} \mathrm{C}$-surface vibrations are between 400 and $600 \mathrm{~cm},-1$ and $\mathrm{CH}$ stretching frequencies are around $3050 \mathrm{~cm}^{-1}$ in both $\mathrm{CH}$ and $\mathrm{CH}_{2}$. The reaction of $\mathrm{CH}+\mathrm{H}=\mathrm{CH}_{2}$ on the nickel surface is $1.45 \mathrm{eV}$ exothermic; however a barrier exists to moving $\mathrm{H}$ to a three-fold site adjacent to one occupied by $\mathrm{CH}$. Energy barriers exist for the approach of $\mathrm{H}$ toward the adsorbed fragments until distances become short enough to begin to establish $\mathrm{C}$-H bonds. Experimental values for the adsorption energies of hydrocarbon fragments on nickel are inferred only indirectly; however, the eaction $\mathrm{CH}_{3}+\mathrm{H}=\mathrm{CH}_{4}$ is known to be nearly energetically neutral as is found by the calculations. Calculations on the dissociation of $\mathrm{CH}_{4}$ on $\mathrm{Ni}(111)$ show that an atop $\mathrm{Ni}$ dissociation site is most favorable energetically, but the calculated barrier to dissociation is quite high, $23 \mathrm{kcal} / \mathrm{mol}$ (11).

During this period, stuuies of the adsorption of $\mathrm{H}_{2} \mathrm{O}$ and $\mathrm{NH}_{3}$ on $\mathrm{Ni}(111)$ were alsc completed $(17,19)$. These lone pair electron species are found to adsorb preferentially at atop Ni sites, but energy differences between the 3-fold, bridge and atop 
sites are calculated to be very small, $<0.2 \mathrm{eV}$. These results are in sharp contrast to those for hydrocarbon and $\mathrm{H}$ atom fragments for which high symmetry sites were energetically preferred. Molecular $\mathrm{H}_{2} \mathrm{O}$ adsorbed on the $\mathrm{Ni}(111)$ surface is found to prefer an atop atom site with an adsorption energy of $12 \mathrm{kcal} / \mathrm{mol}$ and a $\mathrm{Ni}-\mathrm{O}$ equilibrium distance of $2.06 \AA$. The equilibrium geometry of $\mathrm{H}_{2} \mathrm{O}$ is calculated to lie in a plane inclined by about $25^{\circ}$ to the normal to the surface, hut tilting the plane of the molecule from $0^{\circ}$ to $50^{\circ}$ or rotating the molecule about the $\mathrm{Ni}-\mathrm{O}$ axis changes the energy only slightly. The $\mathrm{OH}$ radical binds strongly to the $\mathrm{Ni}(111)$ surface at both three-fold and bridge sites with adsorption energies of $87 \mathrm{kcal} / \mathrm{mol}$ and $\mathrm{Ni}-\mathrm{O}$ bond lengths from 2.02 to $2.08 \AA$. The $\mathrm{OH}$ axis of adsorbed $\mathrm{OH}$ is inclined about $10^{\circ}$ from the surface normal at a three-fold site. Dissociation of $\mathrm{H}_{2} \mathrm{O}$ to $\mathrm{OH}$ and $\mathrm{H}$ adsorbed at nearby three-fold sites is exothermic, and for $\mathrm{OH}$ and $\mathrm{H}$ at a large distance of separation, the reaction $\mathrm{H}_{2} \mathrm{O}(\mathrm{ads})=\mathrm{OH}(\mathrm{ads})+$ $\mathrm{H}(\mathrm{ads})$ is $52 \mathrm{kcal} / \mathrm{mol}$ exothermic. A high energy barrier is found at the initial stage of dissociation. The work function decreases by $\approx 0.5 \mathrm{eV}$ on $\mathrm{H}_{2} \mathrm{O}$ adsorption and increases by $\approx 0.2 \mathrm{eV}$ on $\mathrm{OH}$ adsorption (17).

Molecular $\mathrm{NH}_{3}$ adsorbed on the $\mathrm{Ni}(111)$ surface at an atop atom site and a fcc three-fold site as well as a bridge site are of comparable stability, with adsorption energies of $19.4,18.4$ and $17.3 \mathrm{kcal} / \mathrm{mol}$ and with $\mathrm{Ni}-\mathrm{N}$ equilibrium distances of $2.12,2.78$ and $2.74 \AA$, respectively; ammonia bonds to the substrate via the $\mathrm{N}$ atom with the H's pointing away from the surface. The equilibrium geomeiry of $\mathrm{NH}_{3}$ is calculated to have a pyramidal configuration with the molecular axis normal to the substrate, but tilting the rnolecular axis or rotating the molecule about the surface normal requires little energy. Calculated frequencies of the surface- $\mathrm{NH}_{3}$ group vibration, perpendicular to the $\mathrm{Ni}(111)$ surface, are between 460 and $500 \mathrm{~cm}^{-1}$ and the $\mathrm{H}-\mathrm{N}$ stretching frequency in $\mathrm{NH}_{3}$ on the surface is $3340 \mathrm{~cm}^{-1}$. The work function decreases by $\approx 0.6 \mathrm{eV}$ on $\mathrm{NH}_{3}$ adsorption (19).

In studies of benzene adsorption on nickel, $\mathrm{C}_{6} \mathrm{H}_{6}$ is found to be adsorbed molecularly, parallel to the surface, at a three fold site, bonding primarily through its $\pi$ electron system. The equilibrium distance is $2.2 \AA$ from the surface. The calculations show no distortion of the benzene ring other than a 2 percent expansion. C-H bonds tilt away from the surface $8.5^{\circ}$. The adsorption energy is calculated to be $1.2 \mathrm{eV}$. Adsorption 
at the three fold hollow site gives a slightly higher energy than the hop site, but the difference may be within the uncertainty of the calculation. The energy of the bridge adsorption site is higher than that of the hep site by $0.5 \mathrm{eV}$. The photoemission spectrum of adsorbed benzene is explained in terms of final state relaxation effects analogous to image charge formation in the metal following ionization of benzene (18).

The role of $\pi$ bonding in the $(2 \times 1)$ reconstruction of $\operatorname{Si}(111)$ was investigated (1). The difference in total energy $(\Delta \mathrm{E})$ between the planar and twisted Si-Si $\pi$ systems in a single $\pi$ bond $\left(\mathrm{Si}_{2} \mathrm{H}_{4}\right)$, a pair of $\pi$ bonds $\left(\mathrm{Si}_{4} \mathrm{H}_{6}\right)$ and a $\mathrm{Si}_{6}$ chain with $3 \pi$ bonds embedded in an $\mathrm{Si}_{12}$ cluster show a uniform decrease in $\Delta \mathrm{E}$ with the number of $\pi$ bonds. For the largest system studied, a $\mathrm{Si}_{12}$ cluster model of the (111) surface, $\Delta \mathrm{E}$ is negligibly small. These results suggest that the partial breaking of Si-Si $x$ bonds does not energetically inhibit surface reconstruction (5).

Effective core potentials for $\mathrm{Fe}\left(1 \mathrm{~s}-3 \mathrm{p}^{6}\right)$ and $\mathrm{Fe}\left(1 \mathrm{~s}-3 \mathrm{~d}^{7}\right)$ cores have been developed and fully tested by comparison with all-electron SCF and CI calculations of Fe$\mathrm{H}$ and Fe-Fe potential curves. Embedded cluster models for the Fe (110) surface have now been developed and calculations of $\mathrm{H} / \mathrm{Fe}$ performed in preparation for the $\mathrm{H}_{2} / \mathrm{Fe}$ surface studies.

\section{Future Research}

Work planned for the near future includes the investigation of $\mathrm{Si}$ and $\mathrm{SiH}_{\mathrm{x}}$ adsorption and decomposition on silicon surfaces and interactions with a $\mathrm{Si}(100)$ stepped surface in order to better understand surface diffusion and surface layer growth. Reaction of propene with $\mathrm{Si}(100)$ will also be studied in order to understand mechanisms for depositing $\mathrm{C}$ on silicon by vapor deposition techniques. A third project will involve surface reactions on $\mathrm{Cd}$, Te semiconductor systems. New directions will be explored for the reaction of methane with nickel. Previous results strongly suggest an atop atom site for the $\mathrm{CH}_{4}=\mathrm{CH}_{3}+\mathrm{H}$ reaction, driven by the need to accommodate the products in separated sites on $\mathrm{Ni}(111)$. It is important to investigate the simultaneous involvement of two electronic configurations of $\mathrm{Ni}\left(\mathrm{d}^{9} \mathrm{~s}\right.$ and $\left.\mathrm{d}^{10}\right)$, states known to be important in single $\mathrm{Ni}$ 
atom interactions with $\mathrm{CO}$ and $\mathrm{CH}_{4}$, to determine whether the interaction would lead to a lower calculated barrier for methane dissociation. Substitutional replacement of $\mathrm{Ni}$ by a more reactive transition metal atom will also be investigated to determine if there is sufficient retention of reactivity to induce dissociation of methane. The current theory which permits configuration interaction in the local subspace is ideally suited to address these questions. In collaborative work with P. Cremaschi, hydrogen interactions with $\mathrm{Fe}(110)$ will be calculated to determine vibrational excitations and dissociation probabilities on $\mathrm{H}_{2}$ collision with a Fe wall.

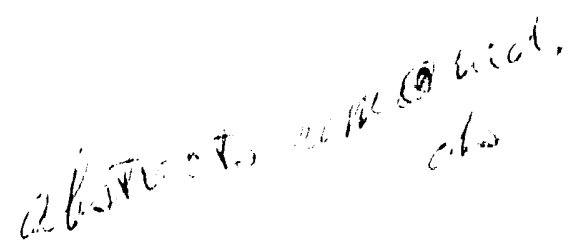




\section{Personnel Supported by DOE Grant}

Graduate student A. Chattopadhyay, $6 / 15 / 87$ to $11 / 1 / 88$

Graduate student H. Yang, 6/15/87 to 8/15/90

Graduate student J. Gladitz, 6/15/87 12/31/89

Graduate student Z. Jing, 6/15/87 to $8 / 30 / 87,1 / 25 / 88$ to $8 / 15 / 90$

Postdoctoral Research Associate, F. Trentini, 3/1/89 to 8/31/89

Visiting Professor C. R. Fischer, 6/15/87 to $8 / 30 / 87$

Principal investigator J. L. Whitten, summer support 1987, 88, 89, academic year at no cost.

Visiting scientist Dr. P. Cremaschi, no cost. 

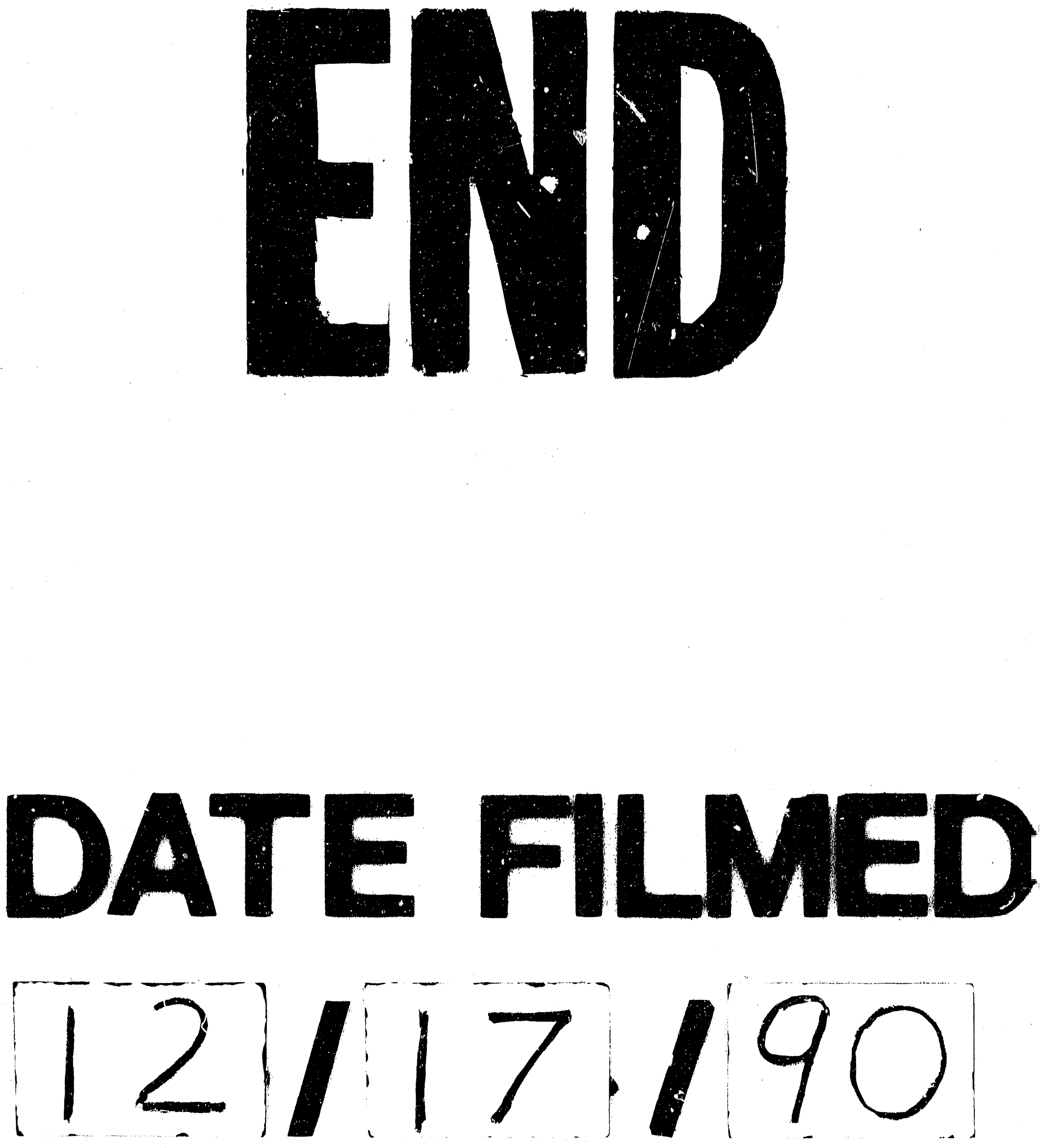
